\title{
Walking the path of desire: evaluating a blended learning approach to developing study skills in a multi-disciplinary group
}

\author{
Michelle Crowther \\ Canterbury Christ Church University, UK
}

\begin{abstract}
This case study describes the methods used to evaluate a series of study skills workshops and online learning materials created for a cohort of foundation degree arts and humanities students. The workshops and online content were created in response to feedback from the previous cohort which revealed that students had struggled to relate the workshops to their assignment, which was a portfolio of critical reflections. In order to better understand the disconnect experienced by the students between the module content and the course assessment, it was decided to track the paths of desire taken by the cohort in their learning, and assess whether online content could improve learning outcomes or whether workshops and print sources are more valuable for skills development. Quantitative data, such as attendance, VLE use and book loans, along with qualitative data from the students' critical reflections were gathered to track student engagement with material, creating a narrative of the learning journeys of the cohort. Findings revealed that online content has a valuable role in supporting success for some students but that attendance at workshops has a strong correlation with portfolio grade and skills development.
\end{abstract}

Keywords: blended learning; study skills; curriculum design and development; higher education; widening participation; foundation degrees; arts and humanities.

\section{Introduction}

High quality university courses are those which engender independence and autonomy in the learner (Ashwin, 2015); however, the 'massification' and consequent diversification of 
higher education in recent years have presented challenges for programme teams in designing study skills material that meets the needs of their students. Widening participation in higher education has made university degree courses accessible to students with additional learning needs, family commitments and varying educational experiences, therefore sensitive and inclusive course design has become paramount so that hegemonic assumptions of knowledge do not suppress and alienate underrepresented groups (Brookfield, 1995).

Evidence suggests that deeper learning takes place in experiential rather than didactic lecture-based skills development programmes (Carbery and Hegarty, 2011) and that the contextualised teaching of study skills within programmes is key to student success (Wingate, 2006); however, the limitations imposed by timetabling, room sizes and staffing has led to the large-scale adoption of generic induction programmes, which can leave students bewildered and poorly-equipped for study (Mery et al, 2012). Blended learning programmes can provide solutions to the ever increasing numbers and diversity of students (Costello, Lenholt and Stryker, 2014; Raven and Rodrigues, 2017) with online material supplementing or replacing generic lectures and providing targeted content to large cohorts (Arnold-Garza, 2014; Hill et al., 2017).

In 2018, Research England encouraged universities to look at metrics such as visits to the library and the speed of clicks on a website to measure student engagement and success. Similarly, UX (user experience) research, which involves systematically investigating the requirements of users, is mapping desire paths around both physical and online spaces (Lee et al, 2016; Massis, 2018). The concept of the 'path of desire' or 'desire path', often defined as the easiest route to one's destination, emerged from the phenomenological methods used by Bachelard (1958) in his work The Poetics of Space. It was decided by the programme team to gather quantitative data, which evidenced the student's physical and online footprint, as well as qualitative data from the student portfolios as part of a phenomenological investigation into their skills development.

\section{Delivery}

In 2017/18, 67 students aged between 17 and 70 on the Arts and Humanities Foundation Degree Programme at a post-1992 university attended a series of six workshops delivered 
by librarians and academic learning developers as part of an Understanding Arts and Humanities module. The students specialised in either an arts or a humanities subject, with between two to twelve students following one of twelve available pathways. As the University is committed to widening participation to non-traditional students, it admits students with a range of backgrounds, disabilities and complex needs. For this cohort, the number of students with declared disabilities was $24 \%, 11 \%$ higher than on any other course at the university. Due to the range of disabilities it was decided to use lecture capture for the module to provide an alternative access route to lecture content.

Each workshop began with an introductory presentation introducing broad concepts such as digital scholarship and publishing, open information and academic integrity, and was followed by activities. Referencing, paraphrasing, plagiarism and the role of plagiarism detection tools were discussed alongside activities about copyright, creative commons and intellectual property rights. There was a firm belief among the programme team that students need a critical understanding of the academic landscape in order to become autonomous learners. It was about putting the 'why' into study skills. The session concluded with a YouTube video from organisations such as the British Library, the National Archives, Turnitin, and the Creative Commons movement. The purpose of the videos was to contextualise academic literacies within arts and humanities scholarship, enabling students to think critically about academic research and its place in society and to develop a holistic understanding of why effective and ethical academic literacy is needed. After the workshop, the students had a one-hour seminar with their course tutors in smaller groups to write critical reflections. Additional material and activities to reinforce learning were made available on the VLE.

\section{Assessment}

The learning outcomes of the module were assessed in the form of a portfolio. Students wrote a 750 word critical reflection about the workshops, discussing how the sessions had informed their approach to research and identifying which essential resources and facilities would help them to undertake research in their degree pathway in the future. The portfolio included a bibliography comprising a range of academic sources to support their understanding of the module. 


\section{Evaluation}

In order to observe the road most travelled, it was important both to identify but also create paths by which students could develop study skills and devise a mechanism to evaluate them. Ethics approval to gather data was obtained from the university's ethics committee. The four routes of engagement or pathways which were identified were: 1) attendance, 2) accesses of digital lecture capture, 3) evidence of use of library resources (print or electronic), and 4) use of the VLE. An effective path was defined as one in which the student attained some measure of success in achieving the learning outcomes of the module, as evidenced through their assessed work.

\section{Attendance}

The University's attendance monitoring system recorded an attendance rate of $61 \%$. For the 46 students who passed the module, the attendance rate was $71 \%$. A Spearman's non-parametric correlation was calculated in order to determine the relationship between student attendance and portfolio grade of those who passed the module. The results of this calculation indicated that there was a significant positive correlation between attendance and grade outcome $\left(r_{\mathrm{s}}=.52, \mathrm{p}<.001, \mathrm{~N}=46\right)$.

\section{Digital lecture capture}

The digital lecture capture videos were accessed 45 times in total. These accesses were made by 16 students, representing $24 \%$ of the cohort, of whom two-thirds had a higher than average attendance $(65 \%)$. This indicates that lecture capture was used not only as an alternative to face to face teaching but also as a recall tool. 29 of the accesses took place during the six weeks that the presentations were delivered, and 16 occurred afterwards in the weeks leading up to the hand-in date for the portfolio. Thirteen of the 16 students who used lecture capture passed the module. The critical reflections revealed that some students considered lecture capture as vital, citing social anxiety and dyslexia as reasons for listening to the recordings. 


\section{Use of library resources}

Library circulation statistics revealed that only two students borrowed the recommended study skills texts and, although both of these students received over $70 \%$ for their portfolio grade, they only represent $20 \%$ of the students in this grade boundary. The bibliographies and critical reflections in the portfolios suggest a higher level of engagement with the material than the library circulation statistics revealed (27\%), indicating that students may have read texts in the library without borrowing them, or obtained required reading from other sources. Accesses to the recommended e-book study skills titles increased significantly during the semester (over 120 accesses in October and November). However, this increase was mainly within the humanities subjects. Some students expressed a preference for printed books in their critical reflections indicating that there is an appetite for textual resources and a more detailed survey of how they obtained this material would be useful.

\section{Blackboard usage}

Blackboard analytics revealed that most of the accesses to the VLE took place on Thursdays (32.21\%) which is the day when the workshops took place. This indicates that students were either using the seminar time after the workshop to view content with their group tutors or spending time in the evening engaging with the online content. The next most popular day was Wednesday, which could suggest that students were either working with the online content or viewing the presentation slides in advance of the workshop. The mean average time students spent using the VLE was 3.01 hours in total over the course of the semester. The mean average for those completing the module was 3.27 hours, rising to 4.20 hours for those passing the module. This equates to 11.66 minutes a week over the 19 weeks from the start of the course until the portfolio submission date. A qualitative analysis was made of the students' portfolios in order to identify whether or not students had engaged with the online activities. Of the 46 students who passed the module, $63 \%$ showed some evidence of engagement with the online content through reflections on using recommended websites, databases, study skills tools or reading.

A Spearman's non-parametric correlation was calculated to determine the relationship between portfolio grade and Blackboard use for those who passed the module. The association between the two variables is not significant for those who passed the module, 
and hours spent on Blackboard did not significantly enhance learning outcomes $\left(r_{\mathrm{s}}=.082\right.$, $\mathrm{p}>.001, \mathrm{~N}=46)$.

\section{Recommendations}

As a result of the case study, changes were made to the module for the $2018 / 19$ cohort. With attendance identified as the most effective path to success more attention was given to creating dynamic content. Presentations were shortened, group work increased, interactive online quizzing introduced and screencasts created. Moreover, in recognition that ease of access is at the heart of desire paths, chapters of recommended study skills texts were scanned and added to the Blackboard to encourage greater engagement with this material at an earlier stage of the module.

Blended learning has the potential to empower and transform the lives of students for whom classroom interaction is difficult and allows for greater subject specificity in targeted content. Thus, it fulfils the needs of a diverse cohort. However, attendance is still key to success for most students. Further research could be undertaken in future cohorts to understand how students develop their academic skills beyond the classroom, looking at class wikis, social media, discussion forums, online modules, and peer to peer support.

\section{References}

Arnold-Garza, S. (2014) 'The flipped classroom teaching model and its use for information literacy instruction', Communications in Information Literacy, 8(1), pp. 722. https://doi.org/10.15760/comminfolit.2014.8.1.161 (Accessed: 19 January 2019).

Ashwin, P. (2015) Reflective teaching in higher education. London: Bloomsbury.

Bachelard, G. (1958) The poetics of space. Reprint, New York: Penguin, 2014.

Brookfield, S. (1995) Becoming a critically reflective teacher. San Francisco: Jossey-Bass.

Carbery, A. and Hegarty, N. (2011) 'Introducing problem-based learning into oneshot information literacy instruction at Waterford Institute of Technology Libraries', 
SCONUL Focus 53(33). Available at:

https://www.sconul.ac.uk/sites/default/files/documents/9 1.pdf (Accessed: 19 January 2019).

Costello, B., Lenholt, R. and Stryker, J. (2004) 'Using Blackboard in library instruction: addressing the learning styles of generations $x$ and $y$ ', The Journal of Academic Librarianship 30(6), pp. 452-460. Available at:

https://doi.org/10.1016/..acalib.2004.07.003 (Accessed: 19 January 2019).

Hill, T., Chidambaram, L. and Summers, J.D. (2017) 'Playing 'catch up' with blended learning: performance impacts of augmenting classroom instruction with online learning', Behaviour and Information Technology 36(1), pp. 54-62. Available at: https://doi.org/10.1080/0144929X.2016.1189964 (Accessed: 19 January 2019).

Lee, Y.Y., Snajdr, E., Calvert, L. and Smith, A. (2016) Journey from subjective to objective: Capturing user experience. Available at: https://scholarworks.iupui.edu/handle/1805/9198 (Accessed: 19 January 2019).

Massis, B. (2018) 'The user experience (UX) in libraries', Information and Learning Science. Available at: https://doi.org/10.1108/ILS-12-2017-0132 (Accessed: 19 January 2019).

Mery, Y., Newby, J. and Peng, K. (2012) 'Why one-shot information literacy sessions are not the future of instruction: A case for online credit courses', College \& Research Libraries 73(4), pp. 366-377. Available at: https://doi.org/10.5860/crl-271 (Accessed: 19 January 2019).

Raven M. and Rodrigues, D. (2017) 'A Course of Our Own: Taking an Information Literacy Credit Course from Inception to Reality. Partnership', The Canadian Journal of Library and Information Practice and Research 12(1). Available at: https://doi.org/10.21083/partnership.v12i1.3907 (Accessed: 19 January 2019).

Wingate, U. (2006) 'Doing away with 'study skills”, Teaching in Higher Education 
11(4), pp. 457-469. Available at: https://doi.org/10.1080/13562510600874268

(Accessed: 19 January 2019).

\section{Author details}

Michelle Crowther is the Learning and Research Librarian for Humanities at Canterbury Christ Church University. Her research interests include digital humanities, digitized newspaper collections, Victorian periodicals and blended learning. 